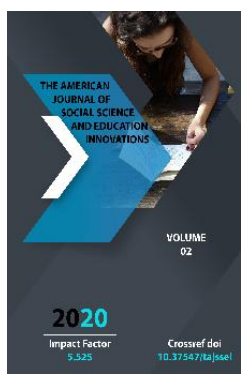

Journal Website: http://usajournalshub.c om/index,php/tajssei

Copyright: Original content from this work may be used under the terms of the creative commons attributes 4.0 licence.

\section{The Role Of Motivation In Learning Foreign Language}

\author{
Muradov Utkir \\ Tashkent State Pedagogical University, Uzbekistan \\ Kadirova Nilufar \\ Tashkent State Pedagogical University, Uzbekistan \\ Ikramova Ra'no \\ Tashkent State Pedagogical University, Uzbekistan \\ Kuchkeldiyeva Umida \\ Tashkent State Pedagogical University, Uzbekistan
}

\title{
ABSTRACT
}

This paper analyzes the role of motivation in language learning, especially foreign language acquisition. It compares two different subjects who are learning English yet they have various background of family, language learning experience, and interests. They were provided pre-, posttests to testify their knowledge; moreover, they were interviewed to know how they are encouraged to learn a language. The paper indicates the importance of intrinsic motivation for second language learners.

\section{KEYWORDS}

Language skills, motivation, knowledge, demotivation, intrinsic motivation.

\section{INTRODUCTION}

The objective need of modern society, especially in the context of the restructuring of all its links, including education, is the search for optimal ways to increase motivation in the study of foreign languages. It seems important that educational institutions test different strategies and ways to increase motivation. The higher the motivation of students, the more fruitful will be the study of a foreign language. Based on the data of pragmalinguistics and taking into account the changed status of a foreign language as a means of communication and mutual understanding in the world community, the modern technique emphasizes the need to strengthen the motivational aspects of language learning. 
Modern psychologists and teachers are united in the fact that the quality of the activity and its outcome depend, first of all, on the motivation and needs of the individual [6], his motivation; it is motivation that causes purposeful activity that determines the choice of means and methods, their ordering to achieve goals. The problem of motivation in learning arises in each studied subject. In appropriate techniques and manuals, methods have been developed for its development and stimulation, taking into account the specifics of the subject. However, the problem of motivation for learning foreign languages is particularly acute. Researchers on the issue of motivation provide data on its decline from class to class. It is noteworthy that until the moment of studying a foreign language and at the very beginning, students usually have high motivation. They want to communicate in a foreign language with peers; it is tempting to recite poems and sing songs in a foreign language; reading to learn about other countries. Many students see in the study of a foreign language something "adventure", penetration into a new unfamiliar world; attractive is the opportunity to transform: "I am a speaker in my native language," "I am a speaker in a foreign language." In a word, almost everyone has a desire to speak a foreign language, to be able to communicate directly, through a book or correspondence. But the mastery of a foreign language begins, and the attitude of students is changing, many are disappointed. Indeed, this process presupposes a period of accumulation of "building material", a stage of inevitably primitive content, overcoming various difficulties, which postpones the achievement of the goals that were dreamed of. As a result, motivation decreases, counteractivity disappears, the will to learn a foreign language weakens, overall performance decreases, which, in turn, negatively affects motivation. And later, as adults, they regret what they missed, dissatisfaction arises not only with oneself, but mainly with the staging of teaching a foreign language. Such is the widely observed picture associated with the study of a foreign language and in technical schools. The analysis of available domestic and Western literature showed the following. At the moment, there is no consensus or unequivocal solution to this problem, namely, what exactly is motivation in general and motivation for educational activities in particular.

The search for ways to solve the question of the motivation of learning is possible in terms of psychological research in this area, which examines the psychological foundations of motivation.

As the world has been found to become like a "global village", English is likely to appear one of the domain languages. The majority of people can learn it as a second language. However, in the second language acquisition, it is irrefutable fact that learners may face several problems including language competence, influence of first language, lexical resource deficiency, even sometimes psychological and emotional attitudes of acquiring a second language yet there are various hypothesis and theories to tackle down these difficulties. So, this case study aims to investigate motivation as a key factor of language learning.

Looking in a little in more detail, in this case study, 2 objects, who are currently studying at the Tashkent State Pedagogical University in the same course with different groups (Russian, Uzbek) whereas own various social background and also language level, have been selected to indicate how motivation impacts on their present study and future plans for educational perspectives.

Main objectives of this case study are threefold:

To analyze motivation as a main factor of learning language more effectively like strong self-study skills 
- To find out motivation as a tool of language acquisition whether continuing a career or learning the culture of second language group

- $\quad$ To investigate why motivation might disappear (demotivation, a motivation)

During the observation, subjects have been asked some tasks to do, given general questions, additionally, some research work, articles which are relevant for the case study have been learnt and collected to compare with the case study.

\section{LITERATURE REVIEW}

Initially, the first time when a new language is introduced to a learner, first language may totally affect to comprehend some new rules. Moreover, some people start learning when they are old enough after critical period. Although aforementioned trouble or other problematic issues will be obstacle for language learning, some of the candidates reveal high language proficiency within different language skills. In fact, taking into count their language capacity, emotional status mostly something fosters them to be the best learners. It is exactly motivation.

Initially, motivation has been found to be one of the most important factors in language acquisition showing motivation as the second strongest predictor of success in language learning after only aptitude [1]. It mostly leads to an exact goal, changes in behavior (a desire to make parents happy by personal achievements, various effective study habits) a strong willingness to accomplish the goal and other attitudes. Furthermore, Susan (2008) assumed motivation owns a function of time and success, precisely, motivation is not permanent, it doesn't stay the same that it was. Sometimes alterations happen till reaching success. As a result, it can include some stages such as preactional stage motivating generally to choose aim, actional stage staying encouraged despite trouble and postactional stage finalizing the attempts and observing the results and achievement [2].

However, succeeding in obtaining the goal easily or hard may influence lessening motivational arousal (motivational excitement).

According to I. Zimney, "the motive is what explains the nature of the given speech action, while the communicative intention expresses what communicative goal is pursued by the speaker planning some form of influence on the listener." [5].

Another approval about motivation is provided by Belles - Fortuno that motivation is initially essential point of learning languages in comparison with other affective factors like age, culture, gender, identity and others. To prove this idea, it is selected two different group learners who were edified in secondary education in vocational training and higher education learners as subjects and compared with each other how they are fostered to study. In fact, they had compulsory English level in vocational training which made them study. They have been checked by giving multifarious questionnaires including "agree, disagree" - based questions, yes-no and whquestions as well as some other questions depending written answers. All data and findings were collected and the total result revealed that university students became better learners due to their inner motivation rather than their opposite representators. Interesting fact that even a language and its culture or friendly atmosphere between a teacher and students, good marks can't encourage students to learn a language as their internal desire -intrinsic motivation [3].

Looking through different sources for the case study, the researcher has analyzed that the majority of researchers have used Dornyeni's approvals in their research work due to the fact that he provides more and 
different data about what motivation is, its types and also he shows other linguists' thoughts. To be more precise, motivation is shown as it has responsibility for identifying human behavior via directing or making it energetic. According to Dornyei (1998), motivation is general term of several factors; it doesn't have specific, certain definition like whether it is affect, cognition, mental energy or response to stimuli, inner force. Unique part of this research is selecting motivation as a process demanding mental procedure! He says: "motivation is defining it as a process whereby a certain amount of instigation force arises, initiates action, and as long as no other force comes into play to weaken it" (Dornyei,1998). In addition, it accounts for three main components, motivational intensity indicating motivated behavior, desire to learn language and attitude towards the act of learning. It has instrumental and integrative elements (in Gardner's it is called the orientations). The former is practical quality and the latter is social and cultural values. He also states that in learning situational level, it has some components. For instance, they are course-specific, teacher-specific, and Group specific motivational components.

Another point of this research, gender is likely to distinguish in language learning motivation. Finally, He also suggests ten main instructions to motivate language learners.

Another research merely focused on intrinsic and extrinsic motivation of people in language learning. "Motivation itself derives from the Latin verb "movera" which means 'to move'. Motivation influences to perform action and make some choices. It is described with two terms: motivation and magnitude" [4]. One is eager to learn a language just for fun or according to his interest yet another may learn it owing to having external desire which affects to learn it. Intrinsically motivated learners own their self-desire, self- study skills. Actually, intrinsic motivation firstly was found in animal behavior that they act curiously and playfully without any prize or response for their action. Likely, some people are also talented at learning a language naturally just for themselves yet others may study because of avoiding punishment or achieving good marks. These both motivation types are linked to each other. For example, internally encouraged people may be bored to sit under strict classroom rules but social approvals or good evaluation are supposed to make him motivated. He also defined integrative and instrumental types of motivation.

Finally, after looking through and analyzing some facts, the researcher is going to conduct her case study using Susan's approvals about motivation and its types, how a factor of time may influence it.

\section{Participant profile}

Initially, to analyze how motivation can impact on second language learning, two subjects were selected. They are studying at the Tashkent State Pedagogical University, in the same faculty- "Foreign language and its literature", as 2nd course students. However, they have a huge difference in their social and cultural background, first language acquisition.

The first subject is A.Z. who was born in 1993. Between 2000 and 2009, he studied at secondary school and continued it in the college of Economy till 2012. Z started learning English in 2008 when he was an applicant. He failed twice in higher education and also stopped learning English for some years due to working in the market. After several years' attempt, he became a student in 2017. His first language is Uzbek, but he had a strong desire to continue his educational process even though in his family background, most of the members are just businessmen and there was no language learning atmosphere. They made him stop applying for the university yet he didn't give up. The most interesting fact is that he didn't know Russian as well, but now he is 
studying at Euro group whose first language is Russian and has been learning Russian language. After gaining enough experience in Russian, now he is preparing for IELTS exam course.

The second subject of this case study is T. S., 20-year- old girl. She started her secondary education in 2005 and continued in Economy College till 2017, entering the university. Her first language is Uzbek, but in her family Russian is a bit predominant so she applied for Russian group. A glance at her family background, her mother is an English teacher and also the other members of family are welleducated. Now, she is studying at intensive course of IELTS as well.

\section{RESEARCH DESIGN}

Primarily, two subjects were observed during some days to analyze their habits, interests, hours spending learning a language and both have problems with different skills of English. For the beginning, they did pre-test to analyze what kind of knowledge level they have, and then they were provided opinion-based test materials to investigate their approvals about English. In the following, some example questions are given (the full questions and answers see in the Appendix):

1. Speaking in English is my

- $\quad$ enthusiasm

- $\quad$ hobby

- challenge

- $\quad$ irritation

- $\quad$ others

2. While speaking in English I feel

- confident

- embarrassed

- shy

- nervous

- others

3. I want to improve my English proficiency because:

- I want to get a better job
- I want to make a good impression about me among people

- I want to visit a foreign country where knowing English is a must

- It is mandatory for my educational institute e) any other

They chose the answers as their desire. In the next part, they were asked to write a mini essay on the theme of "Why is English important for me?" including the importance of a language and reasons of learning it (it is also attached in Appendix).

Finally, they were called for an interview to ask some questions about themselves and their learning habits. For instance, with the first subject, Z:

R: Could you tell me any English course that you have found boring and explain why?

Z: It was my phonetic course in my university. It was really boring. Tell the truth, I did not understand teacher's explanation and the course book was a bit confused and tedious for me.

The latter subject, S responded with another way:

R: Could you tell me any English courses that you have found boring and explain why?

S: When I started learning English 5 years ago I went to tutorial courses and my first lesson was very boring because I could not understand this language

\section{DATA COLLECTION AND FINDINGS}

The most interesting part of the case study is gathering all data and comparing the results within two subjects. According to the all results, the first subject showed that he is intrinsically motivated then the latter. 
Initial result of the pre- test:

\begin{tabular}{|l|l|l|l|l|}
\hline $\begin{array}{l}\text { Name of the } \\
\text { subject }\end{array}$ & $\begin{array}{l}\text { Number of } \\
\text { questions }\end{array}$ & $\begin{array}{l}\text { Number of } \\
\text { correct } \\
\text { answer }\end{array}$ & $\begin{array}{l}\text { Time } \\
\text { management }\end{array}$ & Level \\
\hline S1- Z & 20 & 17 & $10 \mathrm{~min}$ & intermediate \\
\hline S2-S & 20 & 15 & $15 \mathrm{~min}$ & $\begin{array}{l}\text { Pre- } \\
\text { intermediate }\end{array}$ \\
\hline
\end{tabular}

Firstly, while observing them, one can think that the girl has capacity of learning English the boy. There are several various reasons to prove it. Initially, family background of the female subject is totally opposite of the other. It indicates strong attention to up-bringing of a learner, supportive atmosphere to be educated well, and also the mother who always may help to understand and overcome language learning problems. Another issue is that her gender factor, precisely, she is a girl, she started learning from the early ages but she didn't have to work. Thirdly, the boy has had a gap that he stopped learning and restarted it due to other problems. Especially, the result of test showed their willingness to learn a language. For instance, when they asked why they wanted to improve their English language, the boy answered to visit a foreign country, but for the girl it is only for making good impression amid people. However, during the interview, according to the boy's answers, he has anxiety even he may be easily demotivated due to the teacher's punishment whereas this factor doesn't impact on the girl. Moreover, he is a risk taker when he doesn't know the rule or might face challenges yet it is hardship for the latter to take risks.

On the other hand, according to their essays, the boy has integrative motivation (orientation), he wants to learn a language as he is interested in other culture, communicating with others while $\mathrm{S}$ is learning it due to her mother's demand and working foreign countries or any international companies.

In their intensive course on IELTS, $\mathrm{S}$ is getting much more interested due to the instructor's attitude on her, maybe her group also has motivated her. After two-week observation, post-test was provided again and results showed $\mathrm{S}$ has had a slight increase in both timing and correct answers (S1-18-10min/ S216-12min respectively). 


\section{Post-test results}

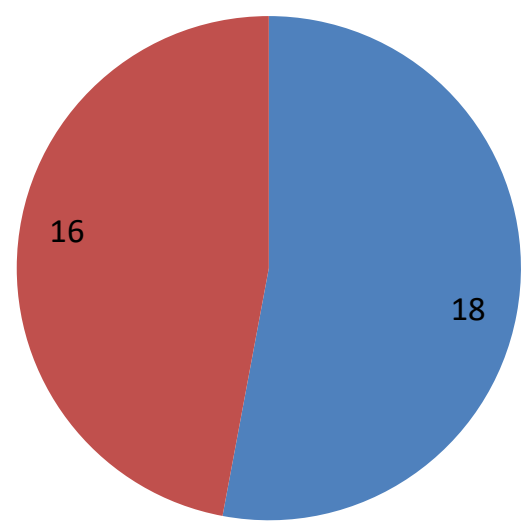

All in all, all things were observed and gathered, one cane state that $Z$ has higher English language proficiency and a strong desire exactly due to intrinsic motivation comparing to $\mathrm{S}$. The reason is that she may lose her interest any period of language learning because of being encouraged external.

\section{CONCLUSION AND FURTHER IMPLICATIONS}

In conclusion of the case study, Susan's research matches with observed subjects' learning. In reality, if a learner is motivated internally, it will be easy to ponder everything with inner desire. Learning obstacle, other impacts which may interfere the learner will be tackled down. However, sometimes motivation types may alter to one another revealing both in one learner like S2 (S)'s awareness of language. Multifarious interesting activities, any type of creative methods, friendly atmosphere in the classroom and supportive teacher and friends has made S2 learn the target language to improve her language skills rather than coming to the lesson under parental supervision or just avoiding punishment of a teacher. Conversely, S1 is continuing to be really encouraged and planning to learn Korean language after becoming advanced level on English language. He himself works on his lexical resource to expand, speak different topics.

As for the further suggestions, S1 should keep improving and practicing in this pace whereas S2 may use different multimedia lessons in order not to be bored and also intensify her understanding in English. It is stated that even movies enable to influence language learning via improving learners' understanding, via subtitles they may boost reading skills and learn some new daily words than academic versions. Additionally, both subjects have a capacity of taking benefits from movies to broaden their horizon on culture of the English- spoken counties later may enhance their interest of learning. Speaking skills, fluency and pronunciation also will be increased by imitating heroes, their appearance and way of speaking. 


\section{REFERENCE}

1. Gass M.S and Selinker L. "Second language acquisition”. Routledge, 2008.

2. Dornyei Z. "Motivation in second and foreign language learning". Cambridge University Press, 1998.

3. Belles- Fortuno B and Ramirez N.O. “ Motivation: a key to success in the foreign language classroom". Valencia, 2015
4. Zaman J. "Role of motivation in second language learning". BRAC,2015

5. Зимняя И. А. - Психологические аспекты обучения говорению на иностранном языке - М.: Просвещение, 1978.

6. 6. O.N.Yusupov. Cognitive semantics in context. Wschodnioeuropejskie Czasopismo Naukowe, №7,2 2016, P.8487 